\title{
Theoretical and experimental studies on theophylline release from hydrophilic alginate nanoparticles
}

\author{
Deepa Thomas ${ }^{1,4}$, Vinish V. Nair ${ }^{2}$, M. S. Latha ${ }^{3,4^{*}}$ (D) and K. Kurien Thomas ${ }^{1}$
}

\begin{abstract}
Background: Mathematical modelling may be able to reduce the number of in vitro experiments and provide an insight into the elementary physical and chemical mechanisms that regulate the rate and degree of drug release. The aim of the present examination was to develop a simple mathematical model to portray drug release from the alginate-type hydrophilic matrix, taking into account the Fickian diffusion of drug and swelling of the matrix using theophylline as the model drug.

Results: The nanoparticles show a remarkable swelling in the simulated intestinal fluid. The theoretical drug release values were validated with experimental values by considering diffusion and diffusion with swelling. The experimental value fitted well with the theoretical value predicted based on diffusion. It was found that after $3 \mathrm{~h}$, the entire drug release followed a pure diffusion transport.

Conclusions: The numerical model was found to be sufficiently accurate in guessing the drug release from the alginate matrix. The developed model could be extended to quantitatively prognosticate the drug release from hydrophilic spherical matrices.
\end{abstract}

Keywords: Matrix, Diffusion, Swelling, Modelling

\section{Background}

During the last decades, drug delivery systems have received considerable attention [1-4]. These systems are intended to offer controlled administration of the pharmaceutical compound to keep their concentration within the therapeutic range. Additionally, they help to reduce the number of drug dosages, initial drug concentration, and side effects due to the unspecific systemic distribution of drugs [5-7]. In vitro drug release studies have been considered as a vital component in the pharmaceutical formulation development. Preliminary data obtained from these studies facilitate the design of the system with optimal in vivo performance. In vitro experiments with varying parameters are required to optimize the device design.

\footnotetext{
* Correspondence: lathams2014@gmail.com

${ }^{3}$ Department of Chemistry, T.K.M.M College, Nangiarkulangara, Harippad, Alappuzha, Kerala 690519, India

${ }^{4}$ Department of Chemistry, Sree Narayana College, Kollam, Kerala 691001, India

Full list of author information is available at the end of the article
}

Mathematical modelling may be able to reduce the number of in vitro experiments and provide a perception of the underlying physical and chemical mechanisms that govern the rate and degree of drug release [8]. Diffusion characteristics, distribution pattern, and loading of a drug in the matrix affect the kinetics and mechanism of drug release [9]. Drug diffusion is significantly influenced by the topology and swelling nature of the matrix. Upon contact with body fluids, the polymer swells and the active ingredient diffuses through the network meshes [10]. The diffusional mass transport assumes a critical part for overcoming the key hindrances, such as mucosa in the gastrointestinal tract [11].

The mathematical model suggested by Higuchi in 1961 based on diffusion mechanism was the first to describe drug release from a matrix system [12]. It may be able to explain the drug release from various pharmaceutical dosage forms [13]. Numerous other models were also formulated to describe the release mechanisms from various polymeric drug delivery systems and most of them involve 
sophisticated mathematical expressions to depict the drug release pattern [14-20]. However, only limited studies have been reported to examine drug release mechanisms from hydrophilic polymer matrices [21, 22].

Alginate (ALG) is a hydrophilic carrier used for the development of oral controlled drug delivery systems. ALG displays a pH-dependent swelling in biological fluids. This property makes alginate an attractive candidate for oral drug delivery applications where the system has to pass through the acidic and alkaline environment [23]. In order to find its application in the pharmaceutical discipline, a detailed knowledge of drug release mechanism and swelling is needed [24]. Even though the swelling nature of alginate was examined by several groups [25-29], only a limited number of mathematical modelling were made on these types of polymer matrix systems [9].

The goal of the current study is to develop a simple mathematical model to describe the drug release from the alginate-type hydrophilic matrix, considering the Fickian diffusion of drugs and swelling of the matrix. A numerical model was developed based on a fully implicit finite difference method. For validating the present model, experiments were conducted with theophylline (THP) as the model drug in $0.1 \mathrm{M}$ phosphate buffer at $\mathrm{pH} 7.4$ and the theoretical values were compared with the obtained data. The effect of different parameters on the release of the drug from the alginate matrix was also evaluated.

\section{Methods}

\section{Materials}

Medium viscosity sodium alginate powder (viscosity of $2 \%$ solution, $25^{\circ} \mathrm{C} \approx 3500 \mathrm{cps}$, Sigma-Aldrich, London), calcium chloride dihydrate (Merck, Germany), theophylline anhydrous with a purity $\geq 99 \%$ (Sigma-Aldrich Chemicals Ltd, USA) were used. All other chemicals used were of analytical grade and were procured locally.

\section{Methods}

Preparation of drug-loaded calcium alginate nanoparticles

THP-loaded calcium alginate (Ca-ALG) was synthesized by an ionotropic gelation technique by following a previously reported procedure with slight modification [30, 31]. Aqueous sodium alginate solution $(1 \%, \mathrm{w} / \mathrm{v})$ was mixed together with honey (added as surfactant and stabilizer). THP was dispersed in the solution at the ratio of $20 \%(\mathrm{w} / \mathrm{w})$ (compared to the weight of Ca-ALG). Aqueous calcium chloride solution $(1 \%, \mathrm{w} / \mathrm{v})$ was added drop-wise into this solution with constant stirring by a magnetic stirrer. This homogenized mixture was sonicated for $5 \mathrm{~min}$. Nanoparticles were collected via centrifugation at $3500 \mathrm{rpm}$ for $5 \mathrm{~min}$, washed, and finally dried under vacuum.

\section{Swelling studies}

The swelling nature of nanoparticles was established by a tea bag technique [32, 33]. A known quantity of dried sample $\left(W_{d}\right)$ was taken in a pre-weighed tea bag (mixed cellulose ester (MCE) membrane of $25 \mathrm{~nm}$ pore size, Millipore) and permitted to swell in a solution of $0.1 \mathrm{M}$ phosphate buffer of $\mathrm{pH} 7.4$ for a particular duration. The swollen samples were withdrawn and weighed instantly after evacuating the excess liquid from the surface with a filter paper $\left(W_{s}\right)$. The swelling percentage was computed using Eq. (1). Each swelling study was performed three times and the average value obtained.

$$
S=\left[\frac{W s-W d}{W d}\right] \times 100
$$

\section{In vitro drug release studies}

In vitro drug release studies were carried out in $0.1 \mathrm{M}$ phosphate buffer, $\mathrm{pH}$ 7.4, as per the United States Pharmacopoeia standard $\left(37^{\circ} \mathrm{C}, 100 \mathrm{rpm}\right)$ [34]. THP concentration was detected using a UV-Vis spectrophotometer (PerkinElmer Lambda Bio 40) at $286 \mathrm{~nm}$ [27]. All experiments were conducted in triplicate.

\section{Mathematical analysis}

Release mechanism Upon contact with simulated fluids, the matrix swells and drug release from the swollen matrix is governed by

1. Advective transport of drug

2. Molecular diffusion

3. Hydrodynamic dispersion within the system

Model assumptions To derive the governing equation of transport, the following assumptions are made regarding drug release from the alginate matrix system.

1. Upon contact with release medium, hydrodynamic dispersion occurs.

2. Matrix swelling is isotropic, ideal, and uniform throughout the device.

3. Perfect sink conditions were kept throughout the study.

4. The dispersion of the drug is uniform within the polymer matrix.

5. No mass loss takes place during the entire process.

It was assumed that the drug diffuses out of the domain in only one dimension. Therefore, the drug transport process in the entire system can be portrayed by the one-dimensional equation. The governing transport equation of drug release in the system is derived based 


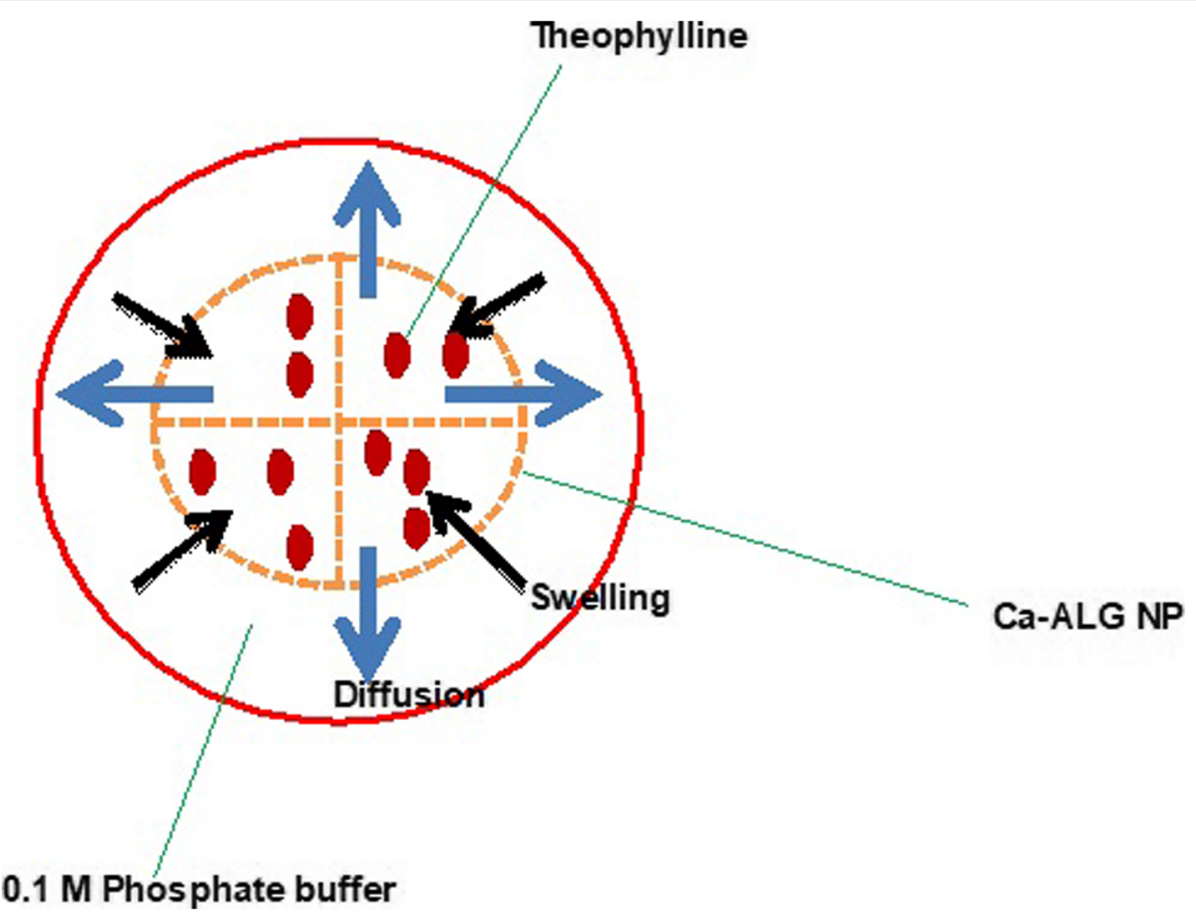

Fig. 1 Schematic of the drug-loaded spherical Ca-ALG NP

on the principle of conservation of mass for an element in the system and is given as

$$
\frac{\partial C}{\partial t}=D \frac{\partial^{2} C}{\partial x^{2}}-v \frac{\partial C}{\partial x}
$$

where $C$ is the concentration of drug in the system $\left(\mathrm{M} \mathrm{L}^{-3}\right), D$ is the hydrodynamic dispersion coefficient $\left(\mathrm{L}^{2} \mathrm{~T}^{-1}\right), v$ is the average velocity $\left(\mathrm{L} \mathrm{T}^{-1}\right), t$ is time, and $x$ is the distance along the axis. The drug diffusion coefficient $D$ can be found experimentally by the reported method [35-37]. Although the velocity may be varying with respect to space and time, in this work the velocity across the entire system is assumed constant and equal to its vertically averaged magnitude. Figure 1 represents the schematic of the drug-loaded spherical calcium alginate nanoparticles (Ca-ALG NP) for mathematical analysis.

The initial and boundary conditions to the problem can be stated as follows:

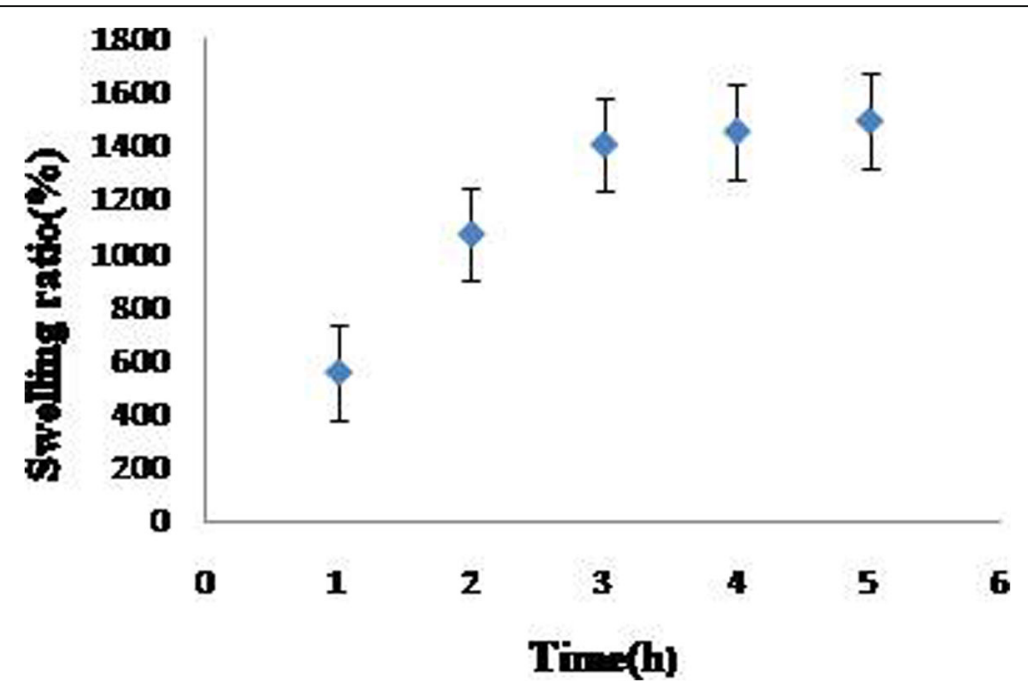

Fig. 2 Swelling kinetics of Ca-ALG NP exposed to phosphate buffer ( $\mathrm{pH} 7.4)$ 


$$
t=0 ; C=0
$$

Initially, the drug concentration at the surface of the matrix is supposed to be equal to zero.

$$
\begin{aligned}
& C\left(0, t_{1}\right)=C_{\max } \\
& C\left(x, t_{1}\right)=0 \\
& C\left(x, t_{\infty}\right)=C_{\text {max }}
\end{aligned}
$$

Equation (4) corresponds to the inlet boundary condition, which represents the concentration of the drug at the point of release. Equation (5) represents the outlet boundary condition in the system and Eq. (6) implies that after a particular time maximum drug release is achieved and it remains constant in the system.

\section{Numerical model}

The source code of the numerical model for simulating the drug release was written in MATLAB. The drug transport equations were discretized using a fully implicit numerical scheme of a finite difference method. An upwind implicit scheme was utilized for discretizing the advection part in Eq. (2) whereas a fully implicit scheme was used for discretizing the diffusion part in Eq. (2). Thomas algorithm was employed for solving the resulting set of simultaneous linear algebraic equations. The continuity of fluxes at the drug-matrix interface was ensured by iterating the solution at each time step. A uniform grid size was selected along the axis; finer grids were selected in the matrix whereas relatively larger grid sizes were adopted in the medium. The concentration flux transfer through the drug-matrix interface was accurately modelled by keeping a relatively small grid size at the interface. The validation of the numerical model was done by comparing the numerical model results with the experimentally obtained values.

\section{Results and discussion}

\section{Swelling studies}

ALG is composed of $\beta$-d-mannuronic acid (M) and $\alpha-\mathrm{l}-$ guluronic acid $(G)$ units and has the ability to bind divalent cations like $\mathrm{Ca}^{2+}$, leading to the formation of junction zones. The swelling nature of ALG nanoparticles was evaluated in the simulated intestinal fluid of $\mathrm{pH} 7.4$ at room temperature (Fig. 2). The kinetics and mechanism of drug release was greatly dependant on the swelling nature of the drug carrier. The nanoparticles exhibited a remarkable swelling in the simulated intestinal fluid. At this $\mathrm{pH}$, which is above its pKa value (pKa of ALG = 3.5), all the carboxylate groups of ALG are ionized and increase the electrostatic repulsion between ions. In addition, an ion-exchange process occurs between the $\mathrm{Ca}^{2+}$ ions present in the "egg box" cavity of polyguluronate blocks of ALG and $\mathrm{Na}^{+}$ions of simulated intestinal fluid, which causes an increase in electrostatic repulsions among negatively charged carboxyl groups. Both the effects enhance the anionic density and the hydrophilicity of the polymer and cause a pronounced swelling and relaxation of the chains. After $3 \mathrm{~h}$, the matrix achieved its maximum swelling. As a result, the volume of the system is changed and causes an increase in mobility and drug diffusivity.

\section{Drug release studies}

ALG nanoparticles contain numerous pores. Upon contact with the simulated intestinal fluid, these pores were filled and a part of drug transport occurs by diffusion.

Solubility of THP in water is $8.3 \mathrm{mg} / \mathrm{ml}$ [38]. The high hydrophilic nature of the ALG matrix ensures that the drug is present in the dissolved form on contact with

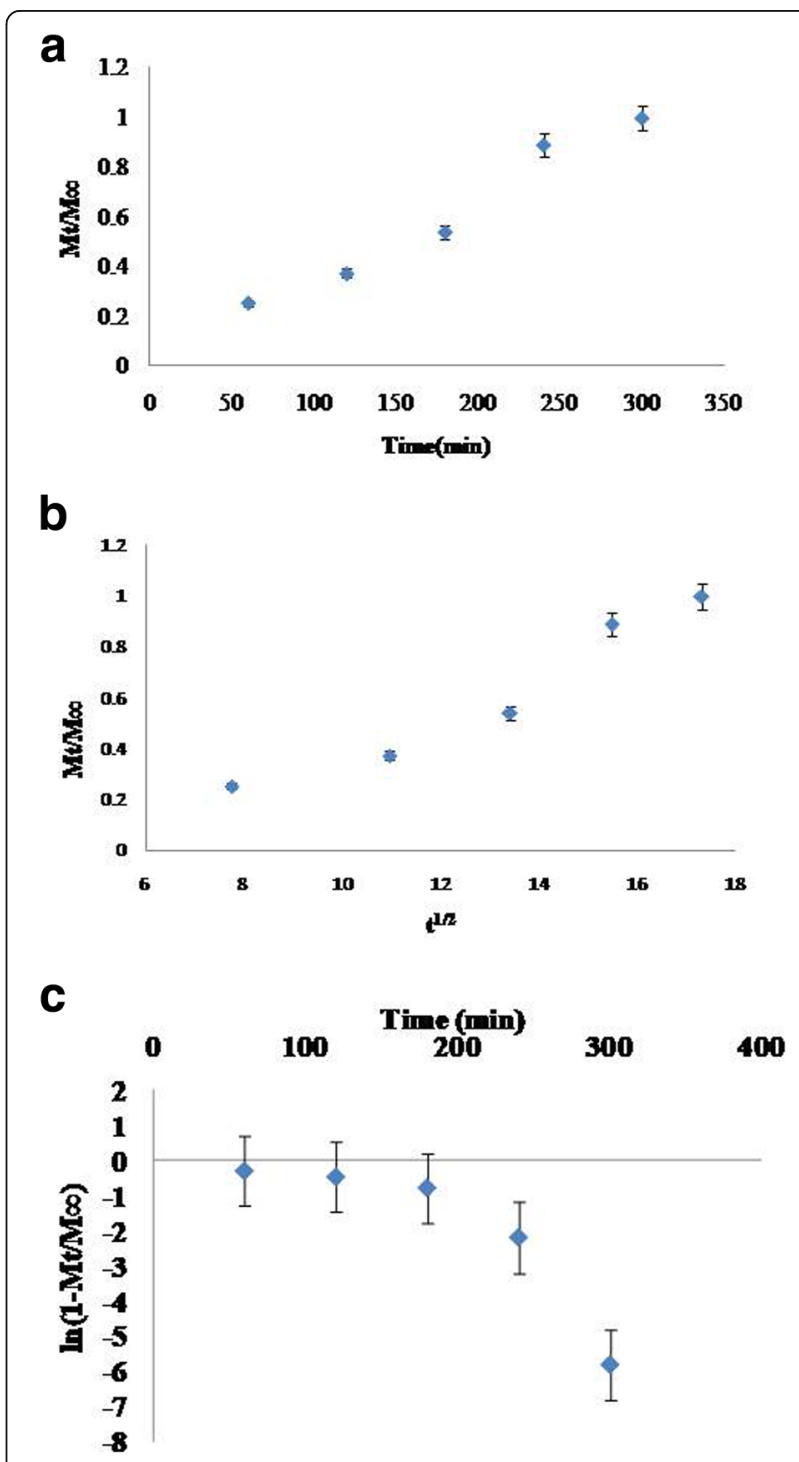

Fig. 3 a The release profile of THP from Ca-ALG NPs as a function of time from Eq. 8. $\mathbf{b}$ The release profile of THP from Ca-ALG NP as a function of square root of time. $\mathbf{c}$ Plot between In $\left(1-M_{t} / M_{\infty}\right)$ and time 
the simulated biological fluid. The percentage of swelling of ALG in the first $1 \mathrm{~h}$ was found to be 600 . Since the maximum drug loading is $60 \%$, the concentration of the drug in the matrix is much lower than its solubility upon swelling. Hence, drug dissolution is not considered for the formulation of the mathematical model.

\section{Determination of diffusion coefficient}

For one-dimensional radial release from a sphere of radius $r$, with a constant drug diffusion coefficient $D$, under a perfect sink condition, the drug release can be expressed by Flick's second law [39, 40] and the solution can be written as

$$
\frac{M_{t}}{M_{\infty}}=1-\frac{6}{\pi^{2}} \exp \left[\frac{-D \pi^{2} t}{r^{2}}\right]
$$

For short time behavior

$$
\frac{M_{t}}{M_{\infty}}=6\left[\frac{D t}{\pi r^{2}}\right]^{\frac{1}{2}}
$$

where $\left(M_{t} / M_{\infty}\right)$ is the fractional release and $M_{t}$ and $M_{\infty}$ are drugs released at time " $t$ " and at equilibrium respectively.

The initial diffusion coefficient $D_{\mathrm{i}}$ and average diffusion coefficient $D_{\mathrm{A}}$ can be calculated from a plot between $\left(M_{t} / M_{\infty}\right)$ and $t^{1 / 2}$ (Fig. 3b).

For calculating $D_{\mathrm{i}}$, the portion of profile up to $\left(M_{t} / M_{\infty}\right)<0.6$ was analyzed, and for calculating $D_{\mathrm{A}}$, the entire portion of the profile $0<\left(M_{t} / M_{\infty}\right)<1.0$ was considered [36].

The late diffusion coefficient $D_{\mathrm{L}}$ can be calculated from the plot between $\ln \left(1-M_{t} / M_{\infty}\right)$ and $t$ (Fig 3c) [37].
The values of $D_{\mathrm{i}}, D_{\mathrm{A}}$, and $D_{\mathrm{L}}$ were calculated as $15.8 \times$ $10^{-2} \mathrm{~cm}^{2} / \mathrm{min}, 22.3 \times 10^{-2} \mathrm{~cm}^{2} / \mathrm{min}$, and $2.1 \times 10^{-2} \mathrm{~cm}^{2} /$ min respectively. While comparing these values, it was found that $D_{\mathrm{A}}$ possesses a higher value than $D_{\mathrm{i}}$ and $D_{\mathrm{L}}$. The smaller $D_{\mathrm{L}}$ value indicates the slow penetration of water into the polymeric matrix during the late stage. However, the value of $D_{\mathrm{A}}$ exactly reflects the changes in the diffusivity during the entire drug release; only the $D_{\mathrm{A}}$ was considered for further calculation.

The experimental release profile from the THP-loaded Ca-ALG nanoparticles is shown in Fig. 3.

\section{Validation of experimental and theoretical results}

Using the theoretical model, drug release was predicted with and without considering swelling, and the comparison is given in Fig. 4 which shows that the experimental value fits well with the theoretical value predicted based on diffusion. However, after $3 \mathrm{~h}$, a deviation was observed for experimental value from the theoretical value calculated considering the diffusion with swelling process. This can be explained by the swelling profile of Ca-ALG NP as shown in Fig. 2. Maximum swelling was achieved in $3 \mathrm{~h}$ and after which the entire drug release was via diffusional transport from the fully swollen hydrogel. The $D_{\mathrm{L}}$ value also supports this observation.

\section{Conclusions}

A mathematical model was developed to depict the drug release from alginate matrix, by considering the Fickian diffusion of the drug from spherical nanoparticles and swelling using THP as the model drug. The initial, average, and late diffusion coefficients were calculated, and average diffusion coefficients were used for

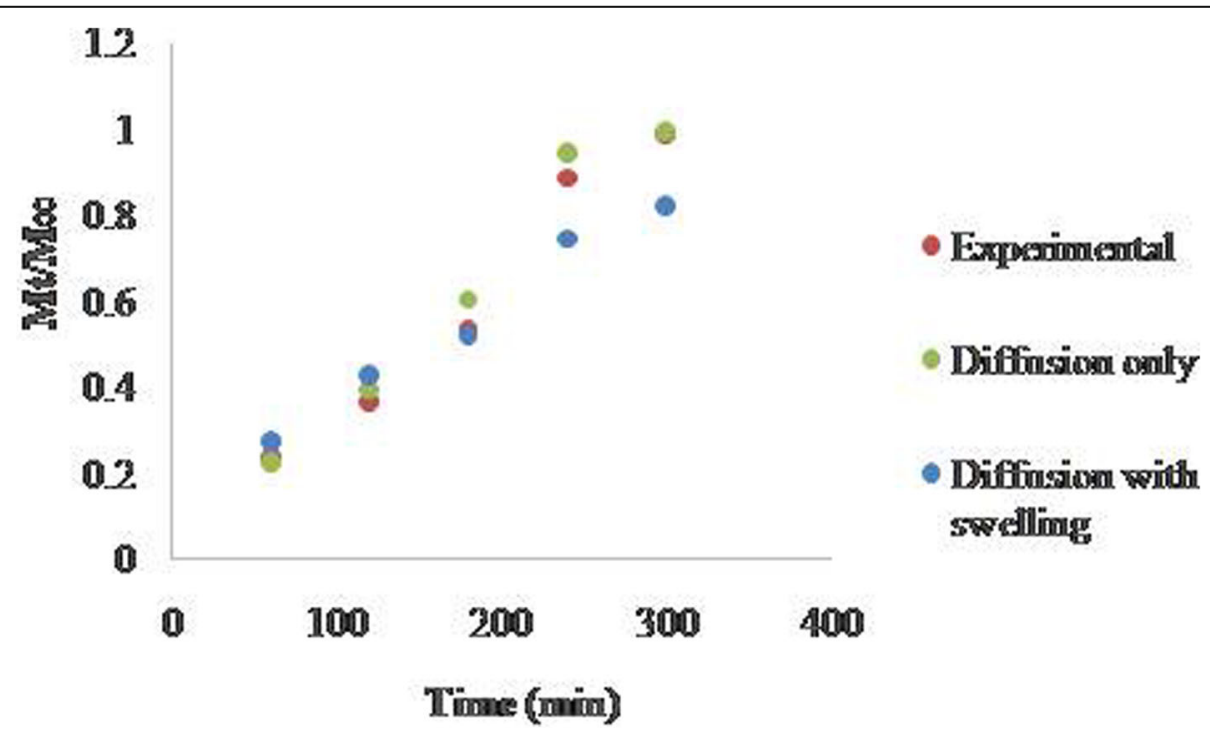

Fig. 4. The validity of the model: predicted with diffusion only, diffusion with swelling, and experimentally determined relative amount of THP release from Ca-ALG NP versus time [release medium: phosphate buffer $(\mathrm{pH} 7.4)$ ] 
further calculation. The theoretical drug release values were validated with experimental values by considering diffusion and diffusion with swelling. It was found that after $3 \mathrm{~h}$, the drug release from fully swollen spherical nanoparticles was purely diffusional transport. The numerical model was found to be sufficiently accurate in predicting the drug release from the alginate matrix. The developed model could be extended for quantitative prediction of drug release from hydrophilic spherical matrices.

\section{Abbrevations}

ALG: Alginate; Ca-ALG: Calcium alginate; Ca-ALG NP: Calcium alginate nanoparticles; MCE: Mixed cellulose esters; THP: Theophylline

\section{Acknowledgements}

The financial support provided by University Grants Commission (FIP/12 plan/KLKE002TF05) India is gratefully acknowledged.

\section{Authors' contributions}

DT carried out the experimental studies and drafted the manuscript. $W$ carried out the theoretical modelling studies. KK helped to design the studies, and MS conceived of the study, participated in its design and coordination, and helped to draft the manuscript. All authors have read and approved the final manuscript.

\section{Funding}

This work was financially supported by University Grants Commission (FIP/12 ${ }^{\text {th }}$ plan/KLKE002TF05) India and is utilized to purchase the chemicals for the study.

\section{Availability of data and materials}

Data will not be shared because it contains unpublished data.

\section{Ethics approval and consent to participate}

Not applicable

\section{Consent for publication}

Not applicable

\section{Competing interests}

The authors declare that they have no competing interests

\section{Author details}

${ }^{1}$ Research and Post Graduate Department of Chemistry, Bishop Moore College, Mavelikara, Kerala 690110, India. ²Department of Civil Engineering, R.I.T Govt. Engineering College, Kottayam, Kerala 686501, India. ${ }^{3}$ Department of Chemistry, T.K.M.M College, Nangiarkulangara, Harippad, Alappuzha, Kerala 690519, India. ${ }^{4}$ Department of Chemistry, Sree Narayana College, Kollam, Kerala 691001, India.

Received: 25 June 2019 Accepted: 30 July 2019

Published online: 02 September 2019

\section{References}

1. Ali A, Ahmed S (2018) A review on chitosan and its nanocomposites in drug delivery. Int. J. Biol. Macromol. 109:273-286. https://doi.org/10.1016/J. IJBIOMAC.2017.12.078

2. Kaur J, Gill GS, Jeet K (2019) Applications of carbon nanotubes in drug delivery: a comprehensive review, Charact. Biol. Nanomater. Drug Deliv:: 113-135. https://doi.org/10.1016/B978-0-12-814031-4.00005-2

3. Carter P, Narasimhan B, Wang Q (2019) Biocompatible nanoparticles and vesicular systems in transdermal drug delivery for various skin diseases. Int J. Pharm. 555:49-62. https://doi.org/10.1016/J.IJPHARM.2018.11.032

4. Masood F (2016) Polymeric nanoparticles for targeted drug delivery system for cancer therapy. Mater. Sci. Eng. C. 60:569-578. https://doi. org/10.1016/J.MSEC.2015.11.067
5. Hoffman AS (2008) The origins and evolution of "controlled" drug delivery systems. J. Control. Release. 132:153-163. https://doi.org/10. 016/j.jconrel.2008.08.012

6. $\quad$ R.S. Langer, New Methods of Drug Delivery, Science (80-. ). 249 (1990) 1527-1533.

7. Langer RS, Peppas NA (1981) Present and future applications of biomaterials in controlled drug delivery systems. Biomaterials. 2:201-214. https://doi. org/10.1016/0142-9612(81)90059-4

8. Ford Versypt AN, Pack DW, Braatz RD (2013) Mathematical modeling of drug delivery from autocatalytically degradable PLGA microspheres - a review. J. Control. Release. 165:29-37. https://doi.org/10.1016/j.jconrel.2012.10.015

9. Grassi M, Colombo I, Lapasin R (2000) Drug release from an ensemble of swellable crosslinked polymer particles. J. Control. Release. 68:97-113. https://doi.org/10.1016/S0168-3659(00)00241-8

10. Saitoh S, Araki Y, Kon R, Katsura H, Taira M (2000) Swelling/deswelling mechanism of calcium alginate gel in aqueous solutions. Dent. Mater. J. 19: 396-404. https://doi.org/10.4012/dmj.19.396

11. Siepmann J, Siepmann F (2013) Mathematical modeling of drug dissolution. Int. J. Pharm. 453:12-24. https://doi.org/10.1016/j.ijpharm.2013.04.044

12. Higuchi T (1961) Rate of release of medicaments from ointment bases containing drugs in suspension. J. Pharm. Sci. 50:874-875. https://doi.org/1 0.1002/jps.2600501018

13. M.H. Shoaib, J. Tazeen, H.A. Merchant, R.I. Yousuf, Evaluation of drug release kinetics from ibuprofen matrix tablets using HPMC., Pak. J. Pharm. Sci. 19 (2006) 119-124. http://www.ncbi.nlm.nih.gov/pubmed/16 751122 (accessed March 16, 2018).

14. Caccavo D, Cascone S, Lamberti G, Barba AA (2015) Controlled drug release from hydrogel-based matrices: experiments and modeling. Int. J. Pharm. 486:144-152. https://doi.org/10.1016/J.IJPHARM.2015.03.054

15. Xie L, Beyer $S$, Vogel V, Wacker MG, Mäntele W (2015) Assessing the drug release from nanoparticles: overcoming the shortcomings of dialysis by using novel optical techniques and a mathematical model. Int. J. Pharm. 488:108-119. https://doi.org/10.1016/J.IJPHARM.2015.03.080

16. Faisant N, Siepmann J, Benoit JP (2002) PLGA-based microparticles: elucidation of mechanisms and a new, simple mathematical model quantifying drug release. Eur. J. Pharm. Sci. 15:355-366. https://doi.org/10.1 016/S0928-0987(02)00023-4

17. Siepmann J, Lecomte F, Bodmeier R (1999) Diffusion-controlled drug delivery systems: calculation of the required composition to achieve desired release profiles. J. Control. Release. 60:379-389. https://doi.org/10.1016/S016 8-3659(99)00093-0

18. Siepmann J, Faisant N, Akiki J, Richard J, Benoit JP (2004) Effect of the size of biodegradable microparticles on drug release: experiment and theory. J. Control. Release. 96:123-134. https://doi.org/10.1016/j.jconrel.2004.01.011

19. Romero G, Murray RA, Qiu Y, Sanz D, Moya SE (2013) Layer by layer surface engineering of poly (lactide-co-glycolide) nanoparticles: a versatile tool for nanoparticle engineering for targeted drug delivery. Sci. China Chem. 56: 1029-1039. https://doi.org/10.1007/s11426-013-4891-z

20. Grassi M, Voinovich D, Franceschinis E, Perissutti B, Filipovic-Grcic J (2003) Theoretical and experimental study on theophylline release from stearic acid cylindrical delivery systems. J. Control. Release. 92:275-289. https://doi. org/10.1016/S0168-3659(03)00330-4

21. J Siepmann, N.A. (2000) Peppas, Hydrophilic Matrices for Controlled Drug Delivery : An Improved Mathematical Model to Predict the Resulting Drug Release Kinetics (the "Sequential Layer" Model), Pharm Res. 17:1290-1298. doi. https://doi.org/10.1023/A:1026455822595.

22. Siepmann J, Kranz H, Peppas NA, Bodmeier R (2000) Calculation of the required size and shape of hydroxypropyl methylcellulose matrices to achieve desired drug release profiles. Int. J. Pharm. 201:151-164. https://doi. org/10.1016/S0378-5173(00)00390-2

23. Tønnesen HH, Karlsen J (2002) Alginate in drug delivery systems. Drug Dev, Ind. Pharm. 28:621-630. https://doi.org/10.1081/DDC-120003853

24. Blanco A, González G, Casanova E, Pirela ME, Briceño A (2013) Mathematical modeling of hydrogels swelling based on the finite element method. Appl. Math. 04:161-170. https://doi.org/10.4236/am.2013.48A022

25. Roger S, Talbot D, Bee A (2006) Preparation and effect of Ca2+ on water solubility, particle release and swelling properties of magnetic alginate films. J. Magn. Magn. Mater. 305:221-227. https://doi.org/10.1016/j.jmmm.2006.01.005

26. Patel N, Lalwani D, Gollmer S, Injeti E, Sari Y, Nesamony J (2016) Development and evaluation of a calcium alginate based ora 
ceftriaxone sodium formulation. Prog. Biomater. 5:117-133. https://doi. org/10.1007/s40204-016-0051-9

27. Lin N, Huang J, Chang PR, Feng L, Yu J (2011) Effect of polysaccharide nanocrystals on structure, properties, and drug release kinetics of alginate-based microspheres. Colloids Surfaces B Biointerfaces. 85:270-279. https://doi.org/10.1 016/J.COLSURFB.2011.02.039

28. V. Pillay, R. Fassihi, In vitro release modulation from crosslinked pellets for site-specific drug delivery to the gastrointestinal tract II. Physicochemical characterization of calcium - alginate, calcium - pectinate and calcium - alginate - pectinate pellets, J. Control. Release. 59 (1999) 243-256.

29. Davidovich-Pinhas M, Bianco-Peled H (2010) A quantitative analysis of alginate swelling. Carbohydr. Polym. 79:1020-1027. https://doi.org/10.1016/j. carbpol.2009.10.036

30. Geetha P, Latha MS, Pillai SS, Deepa B, Santhosh Kumar K, Koshy M (2016) Green synthesis and characterization of alginate nanoparticles and its role as a biosorbent for $\mathrm{Cr}(\mathrm{VI})$ ions. J. Mol. Struct. 1105:54-60. https://doi.org/10.1 016/J.MOLSTRUC.2015.10.022

31. Thomas D, Latha MS, Thomas KK (2018) Synthesis and in vitro evaluation of alginate-cellulose nanocrystal hybrid nanoparticles for the controlled oral delivery of rifampicin. J. Drug Deliv. Sci. Technol. 46:392-399. https://doi. org/10.1016/J.JDDST.2018.06.004

32. Hamidian H, Tavakoli T (2016) Preparation of a new Fe3O4/starch-gpolyester nanocomposite hydrogel and a study on swelling and drug delivery properties. Carbohydr. Polym. 144:140-148. https://doi.org/10.1016/ J.CARBPOL.2016.02.048

33. Al E, Guclu G, lyim TB, Emik S, Ozgumus S (2008) Synthesis and properties of starch-graft-acrylic acid/Na-montmorillonite superabsorbent nanocomposite hydrogels. J. Appl. Polym. Sci. 109:16-22. https://doi.org/10.1002/app

34. U.S.P. Convention, US Pharmacopeia, XXV (2002) 2159.

35. Amsden B (1998) Solute diffusion within hydrogels. Mechanisms and models. Macromolecules. 31:8382-8395. https://doi.org/10.1021/ma980765f

36. Gander B, Beltrami V, Gurny R, Doelker E (1990) Effects of the method of drug incorporation and the size of the monolith on drug release from cross-linked polymers. Int. J. Pharm. 58:63-71. https://doi.org/10.1016/03 78-5173(90)90288-F

37. Singh B, Bala R, Chauhan N (2008) In vitro release dynamics of model drugs from psyllium and acrylic acid based hydrogels for the use in colon specific drug delivery. J. Mater. Sci. Mater. Med. 19:2771-2780. https://doi.org/10.1 007/s10856-008-3406-5

38. Cohen JL (1975) Theophylline. Anal. Profiles Drug Subst. 4:466-493. https:// doi.org/10.1016/S0099-5428(08)60024-6

39. J. Crank, the Mathematics of Diffusion, (1975). doi:https://doi.org/10.1016/03 06-4549(77)90072-X.

40. Ritger PL, Peppas NA (1987) A simple equation for description of solute release I. Fickian and non-fickian release from non-swellable devices in the form of slabs, spheres, cylinders or discs. J. Control. Release. 5:23-36. https:// doi.org/10.1016/0168-3659(87)90034-4

\section{Publisher's Note}

Springer Nature remains neutral with regard to jurisdictional claims in published maps and institutional affiliations.

\section{Submit your manuscript to a SpringerOpen ${ }^{\circ}$ journal and benefit from:}

- Convenient online submission

- Rigorous peer review

- Open access: articles freely available online

High visibility within the field

- Retaining the copyright to your article

Submit your next manuscript at $\boldsymbol{\nabla}$ springeropen.com 